\title{
PROVIDING MASTERS LEVEL COMPUTING STUDENTS WITH REAL-LIFE LEARNING EXPERIENCES VIA CAPSTONE PROJECTS
}

\author{
J. Barrie Thompson, Helen M. Edwards, and Colin J. Hardy \\ School of Computing and Technology, Informatics Centre, University of Sunderland, UK. \\ barrie.thompson@sunderland.ac
}

\begin{abstract}
Within academic programmes real-life learning experiences can be provided in a number of ways: internships/placements, group projects and individual projects. A comparison is made between the mechanisms that can be employed in programmes with a duration of several years compared with intensive taught masters programmes which have a total duration of 12 to 14 months. Details are presented of the range of taught masters programmes in computing that are offered at the University of Sunderland with emphasis on practical parameters and assessment. Actual problems and challenges that have had to be addressed in a changing academic climate are detailed. Finally some overall conclusions and outstanding questions are presented.
\end{abstract}

Key words: Higher Education, Curriculum, Computing, Projects, Industry.

\section{INTRODUCTION}

It is of the greatest importance that the graduates who enter the Information and Communication Technologies (ICT) sector, whether from undergraduate or postgraduate programmes, have appropriate real-life leaning experiences during their programmes so that they can immediately operate in an effective and professional manner. Within 3 and 4 year undergraduate computing programmes that lead to B.Sc. B.Eng. and B.A. degrees, and 4 and 5 year programmes that lead to computing qualifications such as M.Eng., real-life learning experiences can be achieved in a number of ways, for example: 
- By individual placements/internships within industry itself. These may be classed as short term (3 to 6 months duration) or long term. often occupying most of an academic year or even longer ( 9 to 15 months duration).

- By industry-related team/group projects within the body of programmes.

- By industry-related individual student projects that frequently occur in the final year of programmes and which may be a continuation of work which a student has begun during a placement in industry but with a more academic emphasis.

Information on different approaches can be found in the Springer text edited by Holcombe et al. (1998). Of the three listed above, an actual placement within industry is probably the most effective and can bring clear benefits to both the student and the placement organisation (Thompson, 1990). However, experience at our own University has shown, that in the UK at least, the number of students wishing to undertake a long term (one year) placement has fallen dramatically over the last ten years. A driving force behind this trend is clearly student debt. Students want to complete their degree programmes as soon as possible and enter full time employment (hopefully well paid). A clear alternative (and complement) to industrial placements/internships is for academic programmes to incorporate industryrelated projects within the body of their programmes. Many of these are group-based because it is recognised that real-life learning experiences ideally involve working with others. The role and operation of such group projects have been discussed in depth in the papers by Stein (2002 and 2003). However, there can be significant problems in running such group projects as has been made clear by Umpress et al. (2002). Also, as highlighted by Wilde et al. (2003) it is difficult to reproduce all the pressures and constraints of an industrial setting within an academic environment. Many academic programmes include an individual industry-based project in the final year of study as has been described by Beasley (2003) whilst others provide the opportunity for a much more academic orientated research type investigations with an associated dissertation. There is also the possibility of very clear individual assessment within a large group-orientated project - a topic that is addressed in depth by Hayes et al. (2003).

Within the types of computing programmes where students are undertaking their studies over a period of several years it is normally possible to address real-life learning experiences without too much difficulty by adopting one or more of the approaches outlined above. The situation within intensive taught masters programmes that have a total duration of typically 12 to 14 months full-time study (or equivalent part-time) is somewhat different. Although many of the issues which need to be 
addressed are similar to those found in longer programmes, and which are raised in papers such as those by Clear et al. (2001) and Williams et al. (2003), there is nonetheless the facts that these projects:

- need to be at a higher academic level,

- are much more likely to represent an individual piece of work rather than group work,

- tend to involve work that is very intensive, and

- have timescales that are likely to be quite constrained.

In the remainder of this paper we discuss the experiences and lessons that been gained from running capstone projects within intensive taught masters programmes during the last 15 years at the University of Sunderland. In the following section we provide what is essentially contextual information on the range of programmes concerned, their structure, development and the modes of operation. Following that, in the next two sections we provide what may be regarded as idealised views of the project stage within these programs and the assessment of projects. Then in the section headed "If it was only that simple" we look at some of the problems and challenges that we have had to address in a changing academic climate. Finally we present some overall conclusions and outstanding questions.

\section{SUNDERLAND'S MASTERS LEVEL PROGRAMMES IN COMPUTING}

Within the School of Computing and Technology at the University of Sunderland we currently offer a wide range of taught programmes at masters level in both computing and engineering management. The current masters level programmes in computing are: MSc. Computer Based Information Systems, MSc. Information Technology Management, MSc. Electronic Commerce, MSc Software Engineering, MSc. Health Information Management, MSc. Electronic Commerce Applications, MSc. Intelligent Systems, MSc. Network Systems, and MSc Internet Engineering

All the above are offered on-campus and the first three are also available off-campus at distance leaning centres both in the UK and across the globe from Nairobi to Hong Kong. The majority of on-campus students undertake the programmes in full-time mode while the majority of off-campus students study in part-time mode. Each of the programmes consists of three stages: a taught certificate stage that involves the students undertaking four taught modules, a diploma stage that involves the students undertaking a further four taught modules, and finally, a masters stage that consists of an 
individual capstone project for a real-world client. Each of these stages represents 15 weeks of full time study ( $15 \times 40$ hours of student learning). All of the programmes operate within a standard university wide Credit Accumulation and Transfer Scheme (CATS) within which each programme has a value of $180 \mathrm{M}$ (Masters) level points. Full time students can complete the programme within a calendar year though typically they will take 14 months with a break of several weeks between the diploma and masters stages. Part-time students usually take 30 weeks to complete each stage within an overall three-year time span.

The development of the above suite of computing programmes can be traced back to 1989 when the UK Department of Employment, through its Training Agency, was running an initiative known as "High Technology National Training". Through this initiative, funding was awarded (to the then Sunderland Polytechnic) to mount a full-time masters programme in Computer Based Information Systems. The MSc. Information Technology Management programme was introduced in 1992 and then nothing more until the MSc Software Engineering in 1999. Since then there has been a rapid expansion in provision. Over the years different sources of funding have been available to support students on either selected or all the MSc programmes. For example, in the current academic year (2004/2005) some 200 funded places are available to European Union Nationals via the European Social Fund for study on MSc programmes within the School. It is unlikely that without this type of funding it would have been possible to develop such a wide range of programmes. However, programme development has also been driven by opportunities to meet a perceived (and actual) demand for MSc computing programmes by full-fee paying students from the Far East (mainly Mainland China) and the Indian Sub-continent (mainly Pakistan). Further details of the development of the MSc. Computer Based Information Systems programme and the MSc. Software Engineering programme can be found in papers by Thompson and Edwards (1996 and 2003 respectively).

In addition, to offering masters programmes on-campus in both full-time and part-time attendance modes selected programmes have been available in distance learning at approved centres both within the UK and across the world starting with the MSc. Computer Based Information Systems in 1994. The current operational form for distance learning programmes is that teaching materials and assignments are produced by staff at Sunderland. The delivery is face to face at a distance leaning centre by local tutor(s) with support from Sunderland where necessary (often via a video conference link). However, all the students' assignments are assessed by staff at Sunderland. These on-campus and off-campus developments mean that 
currently we have some 500 to 600 students studying masters level computing programmes each year.

\section{PROJECT STAGE}

The overall aim for the project stage in the School's computing programmes is that each student will demonstrate his/her ability to devise and plan, control and execute a substantial project and undertake effective research in the domain. The individual learning outcomes of a typical project with regard to knowledge and abilities are (University of Sunderland, 2004):

- Knowledge of a new area of the programmes discipline (practical and theoretical).

- Ability to effectively scope a project and meet stated objectives.

- Ability to assimilate and disseminate research relevant to the specific project area.

- Ability to use effective time management skills to meet objectives.

- Ability to present the results of a project both verbally and in written form.

- Ability to critically evaluate the work undertaken and the products delivered.

All these represent real-world skills that will support the graduates in their future careers. The practical parameters that are set for each project are (University of Sunderland, 2004):

- The project must have an explicit, identified client.

- The project should take approximately 600 working hours to complete (15 weeks full time work).

- The practical aspect of the project must have a clear link with the subject matter of the specific masters programme being undertaken.

- The practical work must result in a clearly defined product for the client.

- The student must endeavour to ensure that the client carries out a suitable evaluation of the product.

- The project must individual in nature: if it is part of a larger project each student's contribution must be coherent, discrete and well-defined.

- The project must offer sufficient scope for the student to conduct a critical review of current and relevant literature.

- This literature must feed into the practical aspect of the project in some defined manner. 
In all cases the School's main concern is to ensure that the chosen project is of an appropriate standard to warrant the award of an M.Sc. and of a suitable size for it to be completed in the timescale specified.

The important actors involved in each project are:

- The Student

- The Client

- The Project Tutor(s) for the programme who will take overall responsibility for the particular project module

- The Student's Academic Supervisor

- The Second Marker for the project who will be a supervisor for one of the other students.

The client must to be able to identify a product (be it software artefact, strategic study, etc) that is needed by them and is of worth and which represents some 300 hours of practical work (i.e. half the total time for the project). Student and client must consult over the aim, objectives \& procedures for the practical work and this should result in a formal agreement that is "signed off" in the student's project Terms of Reference and product requirements. The client needs to be able to support the student by providing sufficient contact time, any specific facilities (e.g. particular software or hardware), access to relevant documents, and /or personnel as required for the particular project. Also, the client (or his/her organisation) needs be involved in the evaluation of the eventual product.

Each student has an academic supervisor allocated from within the School who will provide regular support and guidance during the project in addition to acting as the fist marker for the project. For distance students, regular communication with their supervisor is through email and where appropriate, by post and video conferencing. There is also support sessions for students at Distance Learning centres via local tutors who can provide face to face discussions on the project work. However, such discussions would be in terms of general support rather than specific direction as this is the role of the supervisor.

The majority of part-time students both on and off campus are in employment and most are able to find a project and sponsor from within their employer's organisation. In fact in many cases their employer may have very specific projects lined up for them prior to starting the final year of their programme. In cases where a part-time student is unable to find such a project the University can offer help as it does for full-time students. The School is particularly proud that in all the years we have been engaged in MSc projects at a distance there has not been an instance where a student has failed to obtain a client. Many full-time students are also able to find their 
own projects, in consultation with the project tutors. This is often via links with previous employers, current part-time employers, family contacts, or through their own particular spheres of interest. The members of the academic staff are also able to identify projects either though their external contacts or research projects. For on-campus students the School is also able to identify some projects via its placement unit for undergraduate students. Also, the University itself provides assistance with projects via its Business Development Unit and its careers service.

\section{ASSESSMENT OF PROJECTS}

The assessment of the projects involves evaluation in five areas: research, success, dissertation, control, and viva. The balance between the assessment areas and the staff involved are detailed in the table below. Very clear guidelines have been published (University of Sunderland, 2004) with regard to the criteria which staff are to use when assessing each of the areas listed in the table. As is made clear in the documentation it is primarily the research element that identifies the project as being of postgraduate standard. Hence it is insufficient for a student to simply achieve a total numerical pass mark for the project. The Research element must also receive at least a pass mark. The research element provides the theoretical underpinning for the project and therefore must be treated in earnest. The research area is assessed according to the extent to which the completed project demonstrates achievement in research and includes an evaluation of the student's ability to:

- Assimilate and disseminate research relevant to the specific project area,

- Critically assess and present this research both verbally and in a written form,

- Relate and apply this review and assessment to the practical elements of the project, and

- Attain a level of expertise beyond that which is achieved in the taught course.

Success of a project is measured with regard to:

- The degree to which the objectives given in the terms of reference have been achieved, and

- The extent to which the deliverables satisfy the project client.

In the assessment of the dissertation, staff are directed to consider:

- The presentation of the initial problem and the results in a wellstructured and logical fashion, 
- How the research literature review has been related to the practical outcome, and

- The student's ability to critically assess the conduct and outcome of the project.

Project Assessment (University of Sunderland, 2004)

\begin{tabular}{|c|c|c|c|}
\hline $\begin{array}{l}\text { Assessors / } \\
\text { Areas (\% of mark) }\end{array}$ & $\begin{array}{c}\text { Project } \\
\text { Review Panel }\end{array}$ & Supervisor & $\begin{array}{l}\text { Second } \\
\text { Marker }\end{array}$ \\
\hline Research $(30 \%)$ & & $\checkmark$ & $\checkmark$ \\
\hline Success & & $\checkmark$ & $\checkmark$ \\
\hline Dissertation $(20 \%)$ & & $\checkmark$ & $\checkmark$ \\
\hline Control & $\checkmark$ & $\checkmark$ & \\
\hline$(15 \%)$ & & $\checkmark$ & $\checkmark$ \\
\hline
\end{tabular}

When they are assessing the control element, the staff are directed to consider the student's capability, motivation, perseverance, resolution, and skill in managing the project. In particular they should focus on the student's ability to plan, schedule, and control the work. It is expected that students will produce and maintain formal Terms of Reference, Schedule and Gantt chart and that these will be included as an appendix in the student's dissertation. Two formal review sessions are held during the project to monitor progress. Wherever feasible these are face to face with School staff (possibly via videoconferencing), though where this is not possible paperbased submissions can be used instead.

Finally, the viva sessions provide a formal opportunity for the students to demonstrate the grasp (or otherwise) they have of their subject to assessors. The viva thus provides a means of ensuring that the student had undertaken the work and had produced the submitted dissertation. It normally consists of a short, focused, presentation followed by a detailed question and answer session. It also provides an opportunity for assessors to resolve any differences they have in their evaluations of the submitted work.

\section{IF IT WAS ONLY THAT SIMPLE}

Until the late 1990s the School was offering only two major MSc. programmes: MSc. Computer Based Information Systems, and MSc. Information Technology Management. These were being offered on and off campus and in both part-time and full-time modes of study. On-campus, the part-time students were nearly all in employment and most found projects with their employer. The same was normally true for part-time students who 
were studying off-campus. On-campus the full-time programmes had reasonable, but not too high, numbers (typically 30/60 per intake), the majority of the students were from the UK, and many had existing links with the immediate geographical area. Finding projects for such students did not present too much of a problem. Many students through their own contacts were able to identify suitable sponsors and the School was able to assist via its placement unit, which at that time was still assisting a fair number of undergraduates with year-long industrial placements. A relatively small number of key staff were involved in the overall management of both on and off campus projects which ensured compatibility of approach and reasonably accurate tracking of each student's progress even when they took breaks, changed modes of study, or had referred work to undertake.

During the last four years (and in particular during the last two years) there have been a significant number of events and situations that have impinged on the project stage of our MSc programmes:

1. The overall number of students undertaking MSc programmes has increased enormously to some 500 to 600 each year (on and off campus total) and these are spread across many programmes.

2. There has been a significant increase in the number of programmes.

3. There has been a significant increase in the number of staff involved in teaching at masters level.

4. The majority of the students are no longer from the UK and hence do not have the same links that will assist them in finding projects local to the University. Students are allowed to take up projects in other parts of the UK or even back in their home countries but this raises extra problems with regard to supervision, control, and tracking.

5. The senior project tutor (with overall responsibility for projects within MSc. Computer Based Information Systems, and MSc. Information Technology Management) with some 13 years of experience with such projects has retired.

6. Relatively few undergraduate students were undertaking placements, the number of staff in the placement unit was reduced, and the number of links with industry via the unit was reduced. Other links with industry have been made via the University's Business Development Unit, the careers service, and the various research groups within the institution. However, these not all these have proved to be as effective in finding projects despite significant expenditure in monetary and staff terms by the Business Development Unit.

7. Differences in approach to obtaining, approving, and managing projects had become apparent across the programmes. 
8. More projects are being undertaken which directly support the research groups within the School. In previous years there had been an insistence that all projects had sponsors from outside the School and ideally from outside the University.

9. Many more staff became involved with MSc. project supervisions (several with little experience of such, or a detailed knowledge of the particular programme which their supervisee was undertaking).

10. Providing and timetabling rooms for reviews and vivas became a major problem. This was for two main reasons: the number of students had increased, and the University was trying to make more efficient use of its buildings by moving part of the School of Education into the building previously occupied only by the School of Computing and Technology.

At the start of the 2003/2004 academic year the first two authors of this paper formally took responsibility for projects for on-campus instances of the MSc. Computer Based Information Systems, the MSc. Information Technology Management, and the MSc Software Engineering. Both had previous extensive experience of programme leadership at masters level and wished to improve external links with industry as they saw this as a means of advancing the University's reach-out and research in Software Engineering. They were subsequently asked to take on overall responsibility for all masters computing projects. This situation lasted for about 4 months and resulted in the production of a single set of documentation for the relevant programmes (University of Sunderland, 2004). Unfortunately, it proved impossible to reach consensus agreement with all the staff involved in the management and running of the various programmes and hence there was a return to the original responsibilities. However, several of the other programme teams have subsequently adopted the procedures that were laid down during those 4 months and are using the assessment and control documents that had been developed. So despite the problems there have been benefits. A clear attempt is being made to introduce more structure into the processes and more formal documentation is generally being used.

\section{CONCLUSIONS}

In this paper we have attempted to provide not only contextual information on a range of masters capstone projects but also details of what could be regarded as good practice with regard to: practical parameters, assessment, and operation across widely distributed centres. We have also provided details of the actual problems that can occur when there is a rapidly 
changing academic climate. It would appear that to run a successful set of projects it is not sufficient to simply address the purely academic issues such as assessment. It is just as important to ensure that the wider issues concerned with obtaining, approving, and managing projects plus providing appropriate academic support are not neglected. Our experiences during the last year have made it clear that to successfully run a large number of these projects there needs to be very clearly documented procedures and support documentation and that intermediate deadlines, as provided by our two interim formal project reviews are essential. However there are still many managerial issues that still need to be resolved such as:

- How should supervisors be chosen and allocated to programmes/projects?

- Should a member of staff act as both sponsor and supervisor for the same project?

- What should happen if a student wishes to change from full-time study to part-time study during the project?

- How should student claims for mitigation be handled? During the project time or after?

- How should late starting projects be handled when there is no reason for the delay?

- How should late starting projects be handled when there is a good reason for the delay?

- How should we handle students who are out of synchronisation with the others due to referrals etc?

- Which staff should be involved in interim reviews?

- What is the best way to manage and support student reviews and vivas?

\section{REFERENCES}

Beasley, R.E. (2003) Conducting a Successful Senior Capstone Course in Computing, Journal of Computing Sciences in Colleges, Vol. 19, Issue 1, October, pp. 122-131.

Clear, T., Goldweber, M., Young, F.H., Leidig P.M., and Scott, K. (2001) ITiCSE 2001 working group reports: Resourcses for Instructors of Capstone Courses in Computing, ACM SIGCSE Bulletin, Vol. 33, Issue 4, December, pp. 93-113

Hayes, J.H., Lethbridge, T.C., and Port, D., (2003) Evaluating Individual Contribution Toward Group Software Engineering Projects, Proceedings of the $25^{\text {th }}$ International Conference on Software Engineering, May, pp. 622-627.

Holcombe, M., Stratton, A., Fincher S., and Griggiths, G. (eds) (1998) Projects in the Computing Curriculum: Proceedings of the Project ' 98 Workshop, Springer, London.

Stein, M.V. (2002) Using large vs. Small Group Projects in Capstone and Software Engineering Courses, Journal of Computing Sciences in Colleges, Vol. 17, Issue 4, march, pp. 1-6. 
Stein, M.V. (2003) Student Effort in Semester-Long and Condensed Capstone Project Courses, Journal of Computing Sciences in Colleges, Vol. 18, Issue 4, June, pp. 200-212.

Thompson J. B. (1990) Preparation for Placement and the Benefits to Employers: A Case Study of Business Computing Students, WCCE/90: Fifth World Conference on Computers in Education, Sydney, Australia, July, pp. 599-604.

Thompson J. B. and Edwards H. M (1996), The Hybrid Manager: Achievement within a World-Wide Dimension, IFIP WG3.4 International Working Conference on Information Technology in Management and Business Education, Melbourne, July, (Proceedings edited by Ben-Zion Barta, Arthur Tatnall and Peter Juliff published by Chapman \& Hall, London 1997, ISBN 0-412-79960-X, “ The Place of Information Technology in Management and Business Education, pp. 199-206).

Thompson J. B. and Edwards H. M. (2003), Reflections on a UK Masters Level Software Engineering Programme Intended for the Home and International Market, Sixteenth Conference on Software Engineering Education and Training (CSEE\&T 2003), 20-23 March, Madrid, Spain, Proceedings published by the IEEE Computer Society, pp.166-173.

University of Sunderland (2004), Computing Masters Projects Handbook, vl.f/t on-campus, School of Computing and Technology, Jan 2004, http://osiris.sunderland.ac.uk/ mcproj/, accessed 25 May 2004.

Umpress, D., Hendrix, T.D., Cross J.C., (2002) Software Process in the Classroom: The Capstone Project Experience, IEEE Software, September, pp. 78-85.

Wilde, N., White, L.J., Kerr, L.B., Ewing, D.D. and Krueger E.A., (2003) Some Experiences with Evolution and Process-Focused Projects, $16^{\text {th }}$ Conference on Software Engineering Education and training (CSEE\&T 2003). March 2003, pp. 242-250.

Williams, J.C., Bair, B., Borstler, J., Lethbridge, T.C., Surendran, K., (2003) Client Sponsored Projects in Software Engineering Courses, ACM SIGSE Bulletin, Proceedings of the 34th SIGCSE Technical Symposium on Computer Science Education, Vol. 35, Issue 1, January, pp. 401-402. 